\title{
Hereditary Kidney Oncocytoma
}

National Cancer Institute

\section{Source}

National Cancer Institute. Hereditary Kidney Oncocytoma. NCI Thesaurus. Code C8960.

An inherited condition characterized by the development of kidney oncocytomas which are often bilateral and multifocal. This condition may be connected to Birt-Hogg-Dube syndrome. 